REPLY

\title{
Correction regarding data on blinatumomab-associated seizures
}

\section{Jacqueline B. Stone and Lisa M. DeAngelis}

We would like to thank Max Topp, Zachary Zimmerman and Hagop Kantarjian for their correspondence on our Review article (Cancer-treatment-induced neurotoxicity - focus on newer treatments. Nat. Rev. Clin. Oncol. 13, 92-105 (2016)) $)^{1}$. After carefully reviewing the data discussed by Topp et al. (Correction regarding data on blinatumomabassociated seizures. Nat. Rev. Clin. Oncol. http://dx.doi.org/10.1038/nrclinonc.2016.133 $(2016))^{2}$, we concur with the authors that the frequency of seizures associated with blinatumomab treatment was overstated in our Review article ${ }^{1}$. As noted in previous studies, the overall rate of grade $\geq 3$ neurological events in patients treated with blinatumomab is $15-20 \%$, and these manifestations include cerebellar signs and encephalopathy, in addition to seizures ${ }^{3}$. Results from two phase II trials ${ }^{4}$ demonstrate that the rate of any neurological event associated with the use of blinatumomab in patients aged $>65$ years was $72 \%$, and in patients under the age of 65 years, this rate was $48 \%$. The authors of the publication on these two trials note an $8 \%$ incidence of convulsions in patients older than 65 years of age who received blinatumomab, and 3\% in those under the age of 65 years ${ }^{4}$. In a multicentre, single-arm, phase II study in patients with relapsed or refractory B-precursor acute lymphoblastic leukaemia treated with blinatumomab $52 \%$ of the patients experienced neurological toxicities, most of which were managed with dexamethasone treatment; $2 \%$ of the patients experienced convulsions. In both of these reports ${ }^{4,5}$, the incidence of convulsions is noted, but the rate of nonconvulsive seizures is not clearly stated. Given that nonconvulsive-seizure activity might present as encephalopathy and aphasia, which are common neurological adverse events that can occur with blinatumomab treatment, the true frequency of seizure associated with this treatment is unknown, and we recommend evaluation for seizure activity if a patient shows signs of altered mental status.

Jacqueline B. Stone and Lisa M. DeAngelis are at the Department of Neurology, Memorial Sloan Kettering Cancer Center, 1275 York Avenue, New York, New York 10065, USA.

Correspondence to J.B.S. stonej3@mskcc.org

doi: $10.1038 /$ nrclinonc. 2016.134

Published online 23 Aug 2016

1. Stone, J. B. \& DeAngelis, L. M. Cancer-treatmentinduced neurotoxicity - focus on newer treatments. Nat. Rev. Clin. Oncol. 13, 92-105 (2016).

2. Topp, M. S., Zimmerman, Z. \& Kantarjian, H. M. Correction regarding data on blinatumomabassociated seizures. Nat. Rev. Clin. Oncol. http://dx.doi.org/10.1038.org/nrclinonc.2015.133 (2016).

3. Magge, R. S. \& DeAngelis, L. M. The double-edged sword: neurotoxicity of chemotherapy. Blood Rev. 29, 93-100 (2015).

4. Kantarjian, H. M. et al. Blinatumomab treatment of older adults with relapsed/refractory B-precursor acute lymphoblastic leukemia: results from 2 phase 2 studies. Cancer 122, 2178-2185 (2016).

5. Topp, M. S. et al. Safety and activity of blinatumomab for adult patients with relapsed or refractory B-precursor acute lymphoblastic leukaemia: a multicentre, single-arm, phase 2 study. Lancet Oncol. 16, 57-66 (2015).

Competing interests statement

The authors declare no competing interests. 